\title{
Stem Cells in Cerebrovascular Diseases
}

\author{
Khalil Hamzi • Brehima Diakite • Sellama Nadifi • \\ Groupe Marocain de Recherche sur les AVC (GMRAVC)
}

Received: 6 March 2013 / Accepted: 18 March 2013 /Published online: 5 April 2013

(C) Springer Science+Business Media New York 2013

\section{Dear Editor,}

Stem cell-based therapeutics for stroke have recently commenced in the clinic (The Stroke Unit Trialists' Collaboration 2007). Despite the advance in our scientific knowledge, cerebrovascular diseases are a major cause of death and disability worldwide. Accordingly, finding a novel treatment, which can be effective well beyond the acute 3-h window after cerebral attack, is being heralded as a unique treatment regimen in the clinic. In recent years, the advancement of stem cell therapy from the laboratory to the clinic has been guided by research recommendations from Stem Cell Therapeutics as an Emerging Paradigm for Stroke (STEPS) (The NINDS rt-PA Stroke Study Group 1995). The consortium guidelines are designed to enhance the safety and efficacy of stem cellbased therapeutics as we translate these novel treatments to stroke patients. The endothelial progenitor cells can take advantage of STEPS as the cells move toward clinical application. Some evidence-based interventions during the acute phase of stroke such as organised stroke unit care and reperfusion therapies with intravenous recombinant tissue plasminogen activator have been recognised to improve the outcome including survival and residual disability that are available only for a minority of patients (Borlongan et al. 2008). Moreover, once cell damage from stroke is established, little can be done to restore pre-stroke conditions. In last years, in the background of this imperative clinical need, hundreds of studies have been published investigating therapeutic potential of stem cell transplantation, on the basis of animal studies showing that cells transplanted to the brain not only survive but also lead to functional improvement in different neurodegenerative diseases models (Lindvall and Kokaia 2006).

K. Hamzi $(\bowtie) \cdot$ B. Diakite $\cdot$ S. Nadifi

Laboratory of Human Genetics and Molecular Pathology, Faculty of Medicine, UH2C, Casablanca, Morocco

e-mail: Khalil.hamzi@gmail.com
Transplanted cells have been hypothesised to be effective not only by cell replacement within the damaged host tissue but also by providing trophic and neuroprotective support as well as immunomodulatory mediators (Locatelli et al. 2009). The existence of endogenous neurogenesis in an adult vertebrate brain was described by Luskin et al. and Alvarez-Buylla et al., who demonstrated for the first time the presence of neuronal stem cells (NSCs) in the adult rodent subventricular zone (SVZ) that migrate out to the olfactory bulb and integrate into the existing neuronal network (rostral migratory stream, RMS) (Luskin et al. 1997). Recently, similar cell populations were identified in the adult human SVZ, with evidence of neurogenesis in the mammalian SVZ and subgranular zone of the dentate gyrus although the existence of the RMS still remains controversial in the human brain (Alvarez-Buylla et al. 2000). Recent studies have detected NSCs in other brain regions, such as the striatum, spinal cord and neocortex (Sanai et al. 2004). Interestingly, the stroke-damaged adult rodent brain preserves some replacement capacity mediated by endogenous NSCs. It is reported that stroke increases the number of newly generated cells in the SVZ in animals (Curtis et al. 2007) and NSCs are able to generate new striatal neurons that migrate to the site of damage for several months after stroke (Lindvall and Kokaia 2006). Stroke infact triggers early expansion of the progenitor pool increasing the fraction of proliferating SVZ cells and shortening the cell cycle length (Kaplan and Bell 1984). In addition to NPCs, stroke induces adult ependymal cells to proliferate and acquire features of radial glial cells (Kuhn et al. 1996). Strikingly, stroke-induced neurogenesis has recently been observed in the adult human brain, even among the elderly (Palmer et al. 1999). Different neurotrophic factors (Yamamoto et al. 2001) are responsible for endogenous neurogenesis stimulation after stroke. Moreover, neuroblasts migrate to the tissue adjacent to the infarct (Zhang et al. 2008a) attracted by matrix metalloproteinases (MMPs), particularly MMP2 (Arvidsson et al. 2002), produced by the compromised 
endothelial cells and by neuroblasts themselves in a loop of endothelial-neuronal interaction. The neuroblasts protective role is reinforced by the fact that they express doublecortin, a marker of cell migration that is shown to be neuroprotective (Arvidsson et al. 2002). In addition, chemotactic signals, particularly SDF/CXCR4, are known to contribute to cell migration. There is also evidence of the beneficial impact of exercise on the functional plasticity after stroke, by providing neurotrophic support to the lesion environment and promoting neural repair. Exercise-induced neurogenesis was confirmed in humans by measuring exercise-specific changes in cerebral blood volume in the adult human dentate gyrus (Zhang et al. 2008b).

The majority of studies to date have shown relatively limited cell replacement from endogenous NSCs and mobilising endogenous NSCs is relatively a new approach. In contrast, researchers has been in progress for decades to replace lost neural cells by transplantation of stem cells from different sources such as foetal embryonic stem cells, neuroepithelial or teratocarcinoma cell lines by using different methods for their isolation and culture. Potential advantages to this approach may include greater control over cell fate, the ability to deliver any desired number of cells and reduced risks associated with mitogen infusion. The major goal is reconstitution of the complex and widespread neuronal-glial-endothelial interrelationship may require access to a broader array of cell lineages, since stroke affects multiple cell types including neurons, glia and endothelial cells. Thus, ideally, cells should need to maintain initially an immature state and differentiate into several specific cell types after engraftment. The host environment plays an important role in this issue by generating appropriate neurogenic signals. Lack of these may divert the cell fate predominantly toward the glial phenotype. Moreover, stem cell transplantation could enhance clinically valuable improvements through several other mechanisms, including growth factor production, endogenous damage-induced plasticity, and local re-innervation, partially due to neuronal replacement (Fig. 1). However, the potential success of transplantation in stroke, in comparison to neurodegenerative diseases, is influenced by some critical issues including anatomy, localization and size of infarct area, time of transplantation, vascular supplies, route and site of implantation and patient selection.

Despite stroke injury being focal, the neuronal degeneration in stroke is not selective but involves different neuronal populations, including glial and endothelial cells, and disrupts various anatomical pathways, including both white and grey matter that need to be restored. In contrast, most experimental studies are conducted using a middle cerebral artery stroke model that presents mostly the striatum and, in a minor part, cortex damage, and only a few authors investigated cell therapy for cortex infarcts (Zhang et al. 2007). Thus, there are not any conclusive results on the possibility of restoring cortical damage and thereby memory and behavioural functions. It can be argued that infarcts associated with cortical involvement are larger and require the reestablishment of essential connections.

The optimal time for cell engraftment after stroke is not yet well defined because of the dynamic modifications of the ischemic lesion's environment over time (Minger et al. 2007). Excitotoxic neurotransmitters, free radicals as well as proinflammatory agents are released in acute phase (Yoshimura et al. 2001). The activated inflammatory response, leading to microglial reaction, together with apoptosis limits both the growth and survival of transplanted cells and endogenous neurogenesis (Nakatomi et al. 2002).
Fig. 1 Stem cell types used in stroke trials and the proposed mechanisms of action (UCB umbilical cord blood, $N S C$ neuronal stem cell, $B M M N C$ bone marrow mononuclear cell, $H S C$ hematopoietic stem cell, MSC mesenchymal stem cell) (Banerjee et al. 2012)

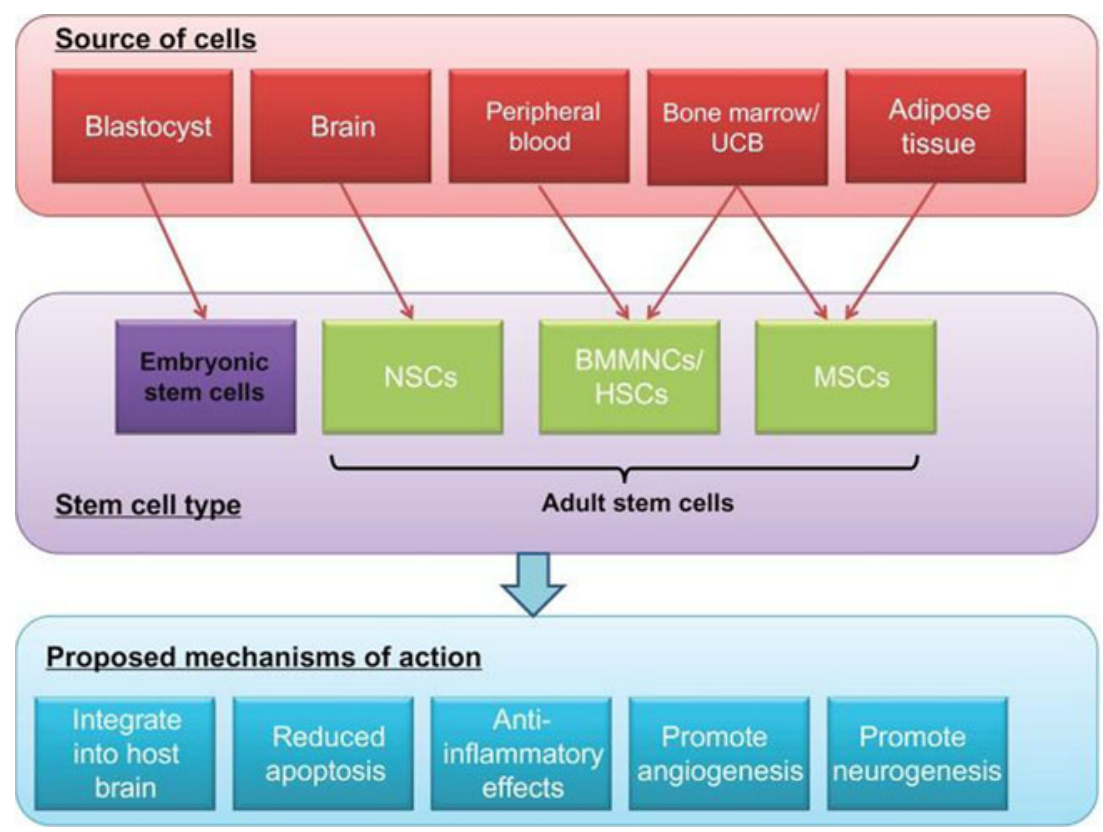


Otherwise, the increased release during the stroke acute phase of cytokines and neurotrophic factors such as granulocyte colony stimulating factor (Teramoto et al. 2003) potentially could favour cell implant survival and growth. In experimental stroke, it has been observed that during the first 2-3 weeks and even longer, the peri-infarct cortex upregulates gene expression related to the modulation of neuronal growth, involving increased expression of cytoskeletal proteins, angiogenesis, cell proliferation, differentiation and migration from SVZ (Pollock et al. 2006). On the other hand, transplantation subsequent to the acute phase encounters difficulties due to the hostile lesion environment generated from the scar tissue formation. Stroke spontaneous recovery depends on brain's plasticity in terms of replacement of afferent and efferent connections and synaptogenesis, which occur early after stroke and last for months or years. There is evidence that these endogenous repair mechanisms can be enhanced by transplantation. In conclusion, it is rational to delay transplantation until neurological deficits reach a plateau and any further spontaneous recovery is unlikely. In studies seeking to demonstrate the generation of new graft-derived circuitry, even greater delays may be employed after injury to ensure stable long-term behavioural deficits prior to transplantation (Pollock et al. 2006).

In conclusion, the field of cell therapy is a very exciting area to develop potential new therapies for stroke. However, the field is still too much in an embryonic and starting stage to make conclusions on its efficiency as a treatment for stroke. There are many unanswered questions surrounding the best cell types, optimal delivery routes, therapeutic time windows and appropriate patients.

Acknowledgements This study was supported by Academy Hassan II of sciences and technology-Stroke project.

Conflict of Interest None declared.

\section{References}

Alvarez-Buylla A, Herrera DG, Wichterle H (2000) The subventricular zone: source of neuronal precursors for brain repair. Prog Brain Res 127:1-11

Arvidsson A, Collin T, Kirik D, Kokaia Z, Lindvall O (2002) Neuronal replacement from endogenous precursors in the adult brain after stroke. Nat Med 8:963-970

Banerjee S, Deborah AW, Nagy H, Jeremy C (2012) The potential benefit of stem cell therapy after stroke: an update. Vasc Health Risk Manag 8:569-580

Borlongan CV, Chopp M, Steinberg GK et al (2008) Potential of stem/progenitor cells in treating stroke: the missing steps in translating cell therapy from laboratory to clinic. Regen Med 3:249-50

Curtis MA, Kam M, Nannmark U, Anderson MF, Axell MZ, Wikkelso C, Holtas S, van Roon Mom WM, Bjork-Eriksson T, Nordborg C,
Frisn J, Dragunow M, Faull RL, Eriksson PS (2007) Human neuroblasts migrate to the olfactory bulb via a lateral ventricular extension. Science 315:1243-1249

Kaplan MS, Bell DH (1984) Mitotic neuroblasts in the 9-day-old and 11-month-old rodent hippocampus. J Neuro Sci 4:1429-1441

Kuhn HG, Dickinson-Anson H, Gage FH (1996) Neurogenesis in the dentate gyrus of the adult rat: age-related decrease of neuronal progenitor proliferation. J Neurosci 16:2027-2033

Lindvall O, Kokaia Z (2006) Stem cells for the treatment of neurological disorders. Nature 441:1094-1096

Locatelli F, Bersano A, Ballabio E, Lanfranconi S, Papadimitriou D, Strazzer S, Bresolin N, Comi GP, Corti S (2009) Stem cell therapy in stroke. Cell Mol Life Sci 66:757-72

Luskin MB, Zigova T, Soteres BJ, Stewart RR (1997) Neuronal progenitor cells derived from the anterior subventricular zone of the neonatal rat forebrain continue to proliferate in vitro and express a neuronal phenotype. Mol Cell Neurosci 8:351-366

Minger SL, Ekonomou A, Carta EM, Chinoy A, Perry RH, Ballard CG (2007) Endogenous neurogenesis in the human brain following cerebral infarction. Regen Med 2:69-74

Nakatomi H, Kuriu T, Okabe S, Yamamoto S, Hatano O, Kawahara N, Tamura A, Kirino T, Nakafuku M (2002) Regeneration of hippocampal pyramidal neurons after ischemic brain injury by recruitment of endogenous neural progenitors. Cell 110:429-441

Palmer TD, Markakis EA, Willhoite AR, Safar F, Gage FH (1999) Fibroblast growth factor-2 activates a latent neurogenic program in neural stem cells from diverse regions of the adult CNS. J Neurosci 19:8487-8497

Pollock K, Stroemer P, Patel S, Stevanato L, Hope A, Miljan E, Dong Z, Hodges H, Price J, Sinden JD (2006) A conditional immortal clonal stem line from human cortical neuroepithelium for the treatment of ischemic stroke. Exp Neurol 199:143-155

Sanai N, Tramontin AD, QuiÇones-Hinojosa A, Barbaro NM, Gupta N, Kunwar S, Lawton MT, McDermott MW, Parsa AT, Manuel Garcìa Verdugo J, Berger MS, Alvarez Buylla A (2004) Unique astrocyte ribbon in adult human brain contains neural stem cells but lacks chain migration. Nature 427:740-744

Teramoto T, Qiu J, Plumier JC, Moskowitz MA (2003) EGF amplifies the replacement of parvalbumin-expressing striatal interneurons after ischemia. J Clin Invest 111:1125-1132

The NINDS rt-PA Stroke Study Group (1995) Tissue plasminogen activator for acute ischemic stroke. N Engl J Med 333:1581-7

The Stroke Unit Trialists' Collaboration (2007) Organised inpatient (stroke unit) care for stroke. Cochrane Database Syst Rev 17(4): CD000197

Yamamoto S, Nagao M, Sugimori M, Kosako H, Nakatom H, Yamamoto N, Takebayashi H, Nabeshima Y, Kitamura T, Weinmaster G, Nakamura K, Nakafuku M (2001) Transcription factor expression and Notch-dependent regulation of neural progenitors in the adult rat spinal cord. J Neurosci 21:9814-9823

Yoshimura S, Takagi Y, Harada J, Teramoto T, Thomas SS, Waeber C, Bakowska JC, Breakefield XO, Moskowitz MA (2001) Fgf-2 regulation of neurogenesis in adult hippocampus after brain injury. Proc Natl Acad Sci U S A 98:5874-5879

Zhang RL, Zhang ZG, Wang Y, Letourneau Y, Liu XS, Zhang X, Gregg SR, Wang L, Chopp M (2007) Stroke induces ependymal cell transformation into radial glia in the subventricular zone of the adult rodent brain. J Cereb Blood Flow Metab 27:1201-1212

Zhang RL, Zhang ZG, Chopp M (2008a) Ischemic stroke and neurogenesis in the subventricular zone. Neuropharmacology $55: 345-52$

Zhang RL, Zhang ZG, Roberts C, Letourneau Y, Lu M, Zhang L, Wang Y, Chopp M (2008b) Lengthening the G(1) phase of neural progenitor cells is concurrent with an increase of symmetric neuron generating division after stroke. J Cereb Blood Flow Metab 28:602-611 